\title{
REMONA Model for Improving Quality of Corporate Informatics Performance Management: How to Cut Cots in Corporate Informatics
}

DOI: 10.12776/QIP.V21I3.939

\author{
Miloš Maryška, Petr Doucek
}

Received: 11 July 2017

Accepted: 02 November 2017

Published: 30 November 2017

\begin{abstract}
Purpose: This paper studies the introduction or increasing of the ability to manage performance in an organization environment. The paper's objective is to facilitate the solution of this problem. Its main goal, meanwhile, is to present the REMONA model and the results of its implementation and to spark professional discussion of the concept behind it.
\end{abstract}

Methodology/Approach: A model will be created to demonstrate the use of the created artifacts within two sub-areas in the environment of two international companies (a consulting firm and an automotive firm) while using the proposed methodology. The model and the methodology will be evaluated for their creation in an organization environment and communication in the entire area.

Findings: Pilot implementation was performed at two companies. It was proven that the proposed REMONA model makes it easier to process and analyze certain financial tasks that are presently considered crucial. The implementation of REMONA model will mainly find use in service or manufacturing companies.

Research Limitation/implication: The REMONA model has only been tested and verified in IT services within service-oriented companies and the automotive industry.

Originality/Value of paper: The paper is valuable for IT managers, and especially CIOs - Chief Information Officers - and project managers. They can find here inspiration for cost allocation, planning, and profitability management in IT services. The article also briefly presents practical experiences with the model's implementation at two international corporations.

Category: Research paper

Keywords: corporate performance management; business informatics; economics efficiency; reference model; business intelligence; data quality 


\section{INTRODUCTION}

As e.g. the publication of Antonova and Zapletalova (Antonová and Zapletalová, 2014) mentions, the worldwide rapid economic growth at the end of the $20^{\text {th }}$ century and during the first years of the $21^{\text {st }}$ century was followed up on with a crisis, from which present economy is still slowly recovering. The crisis brought a change in economic and social paradigms that provoked a bigger pressure on measuring the results quality and performance of not only entire economies but also individual companies and their organizational units. This pressure resulted in the development and gradual implementation of the systems measuring the performance of entire companies, their parts representing organizational or project units or, in some cases, virtual organizational structures (Bjerge, et al., 2016; Doucek, Maryska and Nedomova, 2013). In order for the measurement of economic phenomena, which is necessary for decision-making at all levels of a company's management, to provide a true picture of reality, it is important that the measurement system, including the system of individual indicators, be built on a system approach and thinking (Tavadyan, 2012). Such an approach can be exemplified by the frequently used tools that can generally be referred to as Corporate Performance Management (CPM).

The systems dealing with performance and performance measurement can boldly be described as the most quickly developing area of management of practically all companies. Their added value for all levels of management lies in their ability to provide required data in a required structure and especially at a required time thanks to the integration of information and communication technologies (ICT) (Solodovnikova and Kozmina, 2011; Wade and Recardo, 2001; Wibral, et al., 2013). In view of individual areas of management in a company, CPM tools can include different tools of monitoring the performance of different parts of a company, such as employee performance management, corporate ITC management, sales management, marketing management, etc. A typical example of the structure of CPM components is provided in Fig. 1.

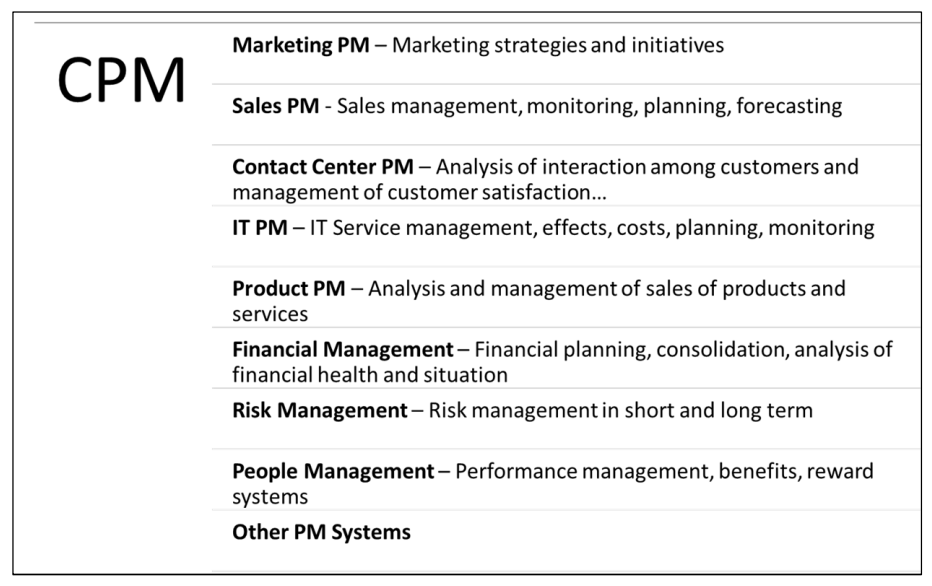

Figure 1 - Diagram of the CPM Concept and Its

Parts (Advanced Performance Institute, 2016) 
A methodological perspective offers another classification of CPM. Its individual areas are characterized in the publications (Cokins, 2009; Dimon, 2013; Eckerson, 2010). These are in particular:

- Budgeting, Planning \& Forecasting. This area focuses on the preparation and creation of plans. Its important part includes support of the management of the processes creating budgets, plans and forecasts of their fulfillment by means of so-called workflow tools.

- Profitability Modeling \& Optimization. This area is mainly based on the application of the so-called "What-If" analysis. Based on the analysis of problems, a manager creates possible scenarios and consequently analyzes their impact on the economic situation of the company and chooses the optimal solution.

- Financial \& Statutory Reporting. This area is based on the requirement to unify the accounting reporting of organizational units of a company in different countries with different local accounting standards. The goal of financial consolidation is to provide an undistorted picture of the finances of a company.

- Financial Consolidation. This is similar to financial and statutory reporting but at the level of an organizational unit. Its goal is to integrate accounting data from different sources in an organizational unit into a consolidated entirety that will permit to evaluate its economic situation. Financial consolidation becomes more important in the case that a company is being fused or restructured.

However, CPM is not presently just a closed topic for a narrow circle of theoreticians; the importance of the research of its individual areas is confirmed not only by the publications of prestigious academic institutions, e.g. Carnegie Mellon Software Engineering Institute (Chrissis, Konrad and Shrum, 2011), the University of California, Berkeley, Cambridge University (Varian, Farrell and Shapiro, 2005), and Czech universities, e.g. the University of Economics in Prague (Wagner, 2009), the University of Tomáš Bat'a (Popesko, 2010), but also by research projects carried out by private consulting corporations, e.g. Ernst and Young (2015) and Gartner (Potter, 2009) and state institutions e.g. in the State of Minnesota (MNsure, 2012). Our ideas for the model that we present here stem from these publications as well as many other documents.

Since the core of our article lies in corporate informatics management or more precisely in the application of the methods of CPM in this area, we needed to also include and to consider in our article the methods, norms and standards that are usually used in this area. It more concerns "good practices" standards that was transformed into internationally respected norms de jure or generally accepted standards de facto. There are many publications in this area as well this topic has been discussed in detail in many studies and publications. The most worldwide used recommendations for corporate informatics management are published in the form of methodological frameworks - CobiT 5 (Isaca, 2012a, 
2012b) and ITIL (Menken, 2011). Both of them similarly focus on corporate informatics management in general and also contain some recommendations, methods and guidelines for the management of the economics of corporate informatics. However, each framework approaches corporate informatics management a little bit differently. The CobiT 5 framework focuses more on the internal processes of management (it was originally created for the top managers of a company so that they could supervise the running of the IT Department via auditors) while the ITIL framework deals with this issue more from the perspective of provided services (the original purpose of this framework was to provide a procedural model for corporate informatics management oriented on the provision of services; its part is presently used as the standard ISO/IEC 20000). A separate part of management, which we also had to take into consideration, includes the indicators and measurement of corporate informatics outputs and performance, which is analyzed in detail in the publications (Grembergen and Haes, 2001; Parmenter, 2010). These publications can be currently considered one of the best and most detailed sources in this area.

The entire group of corporate informatics management tools, sometimes also referred to as IT Governance or the IT Governance Framework, has become a part of the majority of modernly managed companies' management concept, which is referred to as Corporate Governance (Balocco, Ciappini and Rangone, 2013). This interconnects the achievement of a company's strategic goals with the goals and tasks formulated in the information strategy.

In spite of a detailed analysis of the sources concerning CPM, corporate informatics management, IT Governance, Corporate Governance and outputs and performance measurement, we were not able to identify a corporate informatics performance management model (Fig. 1) that would be described in such a comprehensive way so that it could be consistently applied to all areas of the management of the economics of corporate informatics. Besides, the identified models are of a more theoretical nature and do not interconnect its basis with the multidimensional concept of data storing that is nowadays necessary for their implementation.

Based on the research of available world and local literature that was mentioned above, we found out that there was currently no economic model (Dimon, 2013; Grembergen and Haes, 2001; Keating, 2016; Ventana Research, 2012) that comprehensively deals with:

- The key links between the individual levels of corporate management and corporate informatics management;

- The management of the economics of corporate informatics and its tasks, including the tasks of cost allocations and profitability planning and management; 
- Support in solving the problems that arise from corporate informatics management and the management of the economics of corporate informatics but are not handled as mentioned e.g. by Grembergen and Haes (2001), Keating (2016) and Kugel (Ventana Research, 2012).

It's true that exists plenty of proprietary solutions created by companies for their private use only and that are created according to their specific requirements. But general solution that could be fast and easily implemented is missing. This gap is covered by the Reference Model of Optimization of Cost Allocation and Planning for IT Management (REMONA) developed and elaborated on by the authors. It supports the selected processes of the management of the economics of corporate informatics that have a major impact on improving the effectiveness of provided IT products and services in a company.

\section{PROBLEM FORMULATION}

Current IT economic practice missed general solution that could be fast and easily implemented into company and helps this company in management of selected areas like cost allocation based on modern approaches, planning and profitability management lacks a generalised solution that is fast and easily implemented into a company and can help it to manage selected areas such as cost allocation based on modern approaches, planning, and profitability management. This paper's main goal is to resolve this gap.

The paper's main goal is to present the REMONA model, to spark professional discussion of the concept behind it, and to present experience with the verification of this model.

Besides our main goal, which addresses the identified gap in general, we have identified other tasks intended to refine the main problem identified and to specify the limitations and expectations for the REMONA model:

- Analyze cost allocations and profitability planning and management within the context of managing the finances of corporate informatics and its specifics;

- Provide the reporting needed for corporate informatics management;

- Develop a general software application based on the proposed model that can be tailored to the needs of a specific company;

- Verify the developed application by way of its pilot implementation at selected companies.

\section{METHODOLODY}

This paper involves applied research. Within it, we use the Design Science Research Methodology (Peffers, et al., 2007). The phases of this method will be fulfilled as follows. 
Based on a review of the appropriate literature we have determined that due to the weathering of the economic crisis and very unpleasant ecomomic development, there is an increasing tendency to bolster the rational, effective, and effective disclosure of financial and human resources to ICT governance in companies. For example, the literature (Balocco, Ciappini and Rangone, 2013; Dimon, 2013; Cokins, 2009; Ventana Research, 2012; Wagner, 2009) shows that issues of cost management and distribution for individual orders in internal ICT management are not addressed adequately. The overall lack of ICT governance has been identified by us as a missing application to manage corporate ICT performance. The key problem that the paper deals with is the introduction or increasing of the ability to manage performance in an organization environment.

The paper's objective is to facilitate the solution of this problem. The artifact that is intended to help approach the problem is the performance management model, as well as the methodology for its creation within the organization environment. We will prepare a solution for measuring the performance of corporate IT management and verify it in practice. This solution is based on the application of the cost allocation approach in the specific area of business informatics, planning, and the planning-process phase, including the planning workflow and the application of profitability processes and procedures in the area of business informatics. The solution itself is based on the concepts for corporate IT management as it has been addressed at the Faculty of Informatics and Statistics, University of Economics, Prague for over 10 years. The model extends the understanding of the MMDIS (Multidimensional Management and Development of Information Systems) methodology, which is described for example in (Vorisek, Pour and Buchalcevova, 2015; Vorisek and Pour, 2012, 2015). The mental model for this concept is based on the multidimensional concept of enterprise informatics and its management, which distinguishes in particular the following dimensions: hardware, software, data/information, processes, working - the social and ethical dimension, organization and law and economics, and financial management.

The present solution extends and complements the overall concept, in particular in the block of economics and financial management of business informatics.

The development of the model was based on several sequential steps. The first was review of a current situation in the area of financial management, especially as it applies to business informatics. We had to identify whether or not such a model/models exists, and if so, what is missing in the model/models. We then formulated initial concepts, which we validated in practice, and we discussed these concepts with profesionals from practice and various academic institutions. These concepts were also tested at real cases, ultimately leading to the definition of the final concept for the model that is presented in this paper.

Case studies demonstrate the use of the created artifacts within the environment of two international companies (Case Study 1: a consulting services company; Case Study 2: an automotive company) while using the proposed methodology. 
The implementation of the model in each case study was based on five phases:

- Phase 1: Identification of the reason for introducing the REMONA Model at the target company, the business requirements, and the project configuration;

- Phase 2: Analysis;

- Phase 3: Draft data warehouse and ETL for its fulfillment;

- Phase 4: Implementation of ETL and the REMONA Model;

- Phase 5: Testing and verification of the configured REMONA Model.

Each of the companies included in the case studies was from a different industry. This help us to create a model that was more general and thus more usable at a variety of companies.

The data used for the model was provided by the companies from Case Studies 1 and 2. We were using a subset of the real data. "Subset" here means that we did not use all company data (the full history) but rather the last two years only for Case study 1, the last year only for Case study 2 . We used the selected companies' internal data sources, for their example accounting data, management and project management reports, final accounts, balance sheet, cash-flow report, etc. The data was anonymized so that it could be published in the form of reports (Maryska, 2014).

\section{PROPOSED MODEL}

Prior to starting with the proposed new solution, i.e. the modification and expansion of existing processes of business informatics economics management we identified which processes are crucial in business informatics and integrated them into the model.

We divided the processes that we identified in business informatics economics management and specified as a fundamental part of the proposed model into two levels. The first level is represented by the master process, which is built up from second-level processes (sub-processes). We called the master process IS/ICT Economic and Financial Management. The sub-processes are as follows:

- Analysis of IS/ICT costs;

- Analysis of financial requirements;

- Analysis of financial resources for IS/ICT;

- Analysis of planned and executed effects (benefits) created by IS/ICT;

- Planned IS/ICT effects;

- Planned IS/ICT costs;

- Preparation of an IS/ICT investment plan;

- Preparation of an IS/ICT budget;

- Proposal for procurement of financial resources for IS/ICT. 
We defined the basic characteristics for each sub-process, such as data inputs, the procedure for approaching individual activities, the sequence of individual activities in a sub-process, cooperating sub-processes, outputs, and the roles involved in the life cycle of a sub-process. The mutual interaction and sequence of sub-processes are this methodology's fundamental differences relative to the ITIL, CobiT and Val IT methodologies, whose processes are not as detailed and are not incorporated into a comprehensive company-wide process.

In order to utilize the support of Business Intelligence (BI), we proposed suitable dimensions for each sub-process, which represent an analytical viewpoint for the evaluation of the monitored indicators, and indicators, which express numerical values from the viewpoint of different dimensions and allow a detailed data analysis (for more details, see Doucek, Maryska and Nedomova, 2016).

Using research in literature, consultations with the ICT managers at the pilot companies, and survey sampling among economic entities, we identified the dimensions that we consider relevant for business informatics financial management. We defined each dimension as regards:

- Its purpose, a reference-model definition of contents and the link to business processes and management methods;

- The attributes of the dimension's elements and a description of their contents;

- Its overall basic structure; there can be several structures depending on the purpose of its utilization.

During the analysis, we discovered that the borderline between individual groups of dimensions may not be very clear. We thus placed the "borderline" dimensions in the group where, in our opinion, they would be used the most. We divided the dimensions of IS/ICT financial management into the following groups:

- Basic business dimensions, i.e. dimensions regularly used in most BI applications (e.g. time, providers, plan - actual, business goals, business processes, business departments, business customers, etc.);

- Basic informatics dimensions (e.g. databases, projects, services, software, business informatics applications, technical resources, etc.);

- Economic dimensions and performance dimensions (e.g. categories of effects, cost types, budget, financial, and cost accounts).

The configuration of the dimensions is very important for this model, since it determines the basic scope of the analytical and planning applications. Dimensions are covered in detail in (Novotny, 2003).

From the list of indicators proposed in (Novotny, 2003), we selected a set of indicators that corresponded with the needs of business-informatics financial management and expanded this set with other indicators, based on an analysis of information sources and business requirements. In this case, our information sources were e.g. (ITIL, 2001; Isaca, 2012a, 2012b). 
Identification of the methods for identifying and evaluating indicators in mutual relationships is an important part of the model. This part of the solution is described in detail in (Maryska, 2014). The proposed model includes the following procedures:

- Traditional and modern calculation methods (e.g. Activity Based Costing) intended to analyze information on the cost of individual sub-processes, products and services, based on an analysis of activities and relationship quantities;

- Cost/Benefit Analyses (CBA) intended to evaluate and compare the effects and costs of projects, products, and services;

- Earned Value Management focusing on monitoring and evaluating the basic financial parameters in project management, e.g. the labor and time spent on a project and the project's costs, and analyzing some performance characteristics of a final product, e.g. informatics applications.

Traditional methods of project evaluation, e.g. net present value, internal revenue percentage, return on investment, average annual cash-flow, profitability index, payback period, and more.

The proposed model is based on the analysis of the existing models that are specified in previous part of this article, on the business experience of the authors and on the identification of the areas that are not analyzed in the current models and methodologies, yet are very important from the point of view of business practice and scientific theory. The actual proposal is divided into four separate parts:

- Architecture,

- Business logic,

- Data model,

- Service parameters.

The basic conceptual diagram of the REMONA model is shown in Fig. 2. The proposed model is based on the traditional architecture of the CPM solution, which is adapted to the specifics of the area into which the solution is implemented, i.e. also to the specifics of the model, to permit its easy integration into the corporate architecture of a regular company. The target proposal of the REMONA model is covered with a rectangle called "Model REMONA". It contains three basic parts - tasks, dimensions and indicators - and the REMONA application.

The REMONA model covers three basic business tasks that companies currently very often deal with and which were in detailed described above (processes, dimensions, metrics etc). These three general business tasks concerns planning, cost allocations and profitability. For the purposes of their realization, the model proposes dimensions and indicators. Both these components are integrated in the proposed database into multidimensional data cubes that make it 
possible to easily and quickly adapt the model to the needs of a specific company.

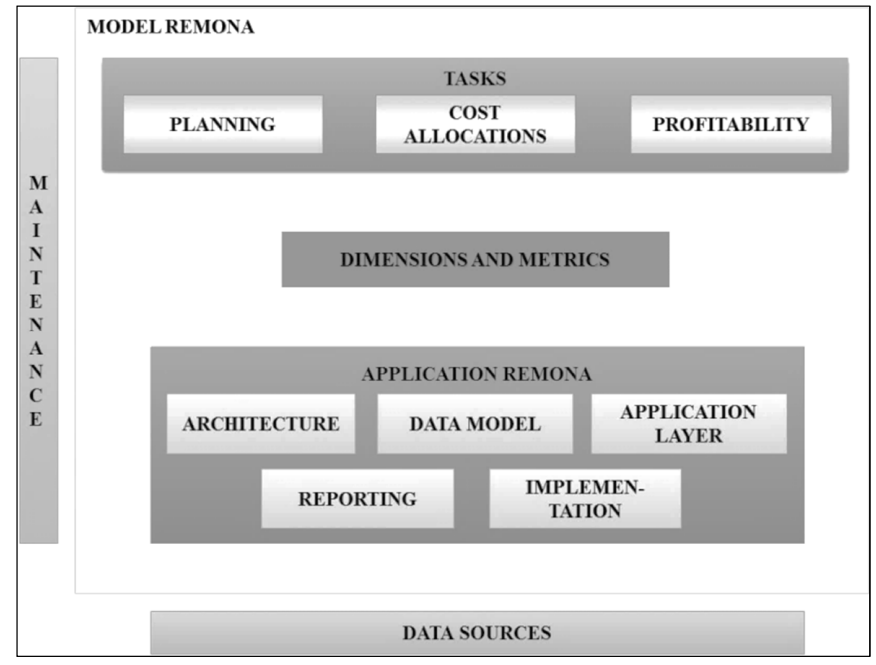

Figure 2-REMONA Model-Conceptual Diagram

The so-far mentioned parts of the model (Tasks, Dimensions and Metrics) describe the model as a theoretical concept, but for the end user it is the application with which he works, i.e. the application support - the "Application REMONA", that is important. Since data sources, which are different in every company, are crucial for any similar application, the proposed model includes its own data model. The application layer represents its own business logic that integrates the mutual links of proposed dimensions and indicators into multidimensional cubes and thus contains the physical realization of the proposed theoretical concept. The key part of the solution from the point of view of the users is the reporting layer that represents the main user interface and the communication tool of the model with the users.

A separate part of the proposed model was its pilot implementation in selected foreign companies.

\subsection{REMONA Architecture of the REMONA Model}

The model architecture that is based on the traditional BI architecture. The architecture of the REMONA model is modified based on its specific needs arising from its implementation in corporate informatics with the goal to permit its easy integration into the corporate architecture of a company.

The proposed application of the REMONA model satisfies the basic postulate that it can be implemented on any platform with multidimensional support (e.g. the platforms Cognos TM1/Express, Oracle Hyperion, MS Sharepoint Server 2014 , etc.). It is thus possible to create dimensions (e.g. time, product) in multidimensional data cubes). 
As an example of this aspect of the proposed solution, we can mention a multidimensional cube with the assumptions of data for planning (the assumptions are the defined parameters that affect the solution as a whole, e.g. planned discounts, value-added tax on provided services, etc.). Such a cube is connected to all other cubes with the data of the plan where it is necessary because of the automated completion of the planning cycle. As an example, we can mention the interconnection of the cube of the assumptions for the plan with the data cube of the planned product contribution that permits to calculate the items derived from the assumptions - e.g. the cost of provided IT services, etc.

The proposed REMONA application includes a general model of the "REMONA Data Warehouse" that is used only for the purposes of the proposed model. This data warehouse/mart supports the realization of the tasks of planning, cost allocation and profitability management as well as the analytical tasks carried out within their context. Some of the key forms and reports supporting the handled tasks are identified at the end user layer.

The solution is proposed from the point of view of end users in such a way so that the reference model would make it possible to:

- Define the business drivers of individual products/services provided by corporate informatics as well as their relation to revenues or costs;

- Easily change and develop the solution - e.g. to change/harmonize the logic of the relation of the business drivers defined for corporate informatics to the revenues from a selected product without any impact of such a change on the logic of the calculation of the revenues from another product;

- Eliminate errors and the risk of creation of different versions of the plan that are not in compliance with the goals of corporate informatics;

- Simplify and well arrange the process of planning thanks to the use of workflow applications;

- Ensure the credibility of the data used for planning and potentially for analyzing as well - thanks to the layer "Data Layer - Data Integration" that will ensure a definite way of importing data from primary data structures;

- Improve the process of cost allocation and of consequent analysis of the profitability of products and services provided by corporate informatics.

The model architecture is based on three basic layers of the solution, i.e.: Data layer; Application layer; End user interface layer.

The "Data layer" solves the tasks concerning the processing of data from primary systems and their storing in the "REMONA Data Warehouse." The layer can be divided into "Data Sources," "Data Integration" and "Data Management."

"Data Sources" are represented by the database of different information systems inside as well as outside a company that provide primary data for the proposed model. Data sources are usually different internal and external databases 
(company data warehouse, transaction systems and other) that are used by different applications supporting main and secondary processes in a company, such as e.g. accounting, quality management, human resources management, etc. In addition to large databases, different small data files or local agendas, e.g. in MS Excel or text files.

The layer "Data Integration" is dealt with ETL tools and data quality assurance tools. The layer "Data Integration" ensures the processing of data from data sources in the form expected by the REMONA data warehouse created for the proposed model.

The key output of the data layer is the created "REMONA Data Warehouse" that represents the database to which the application layer and, through the application layer, the end user interface layer are attached. The data in the data layer are integrated and prepared based on the needs of the application and analytical layer.

The "Application layer" is represented by the tools that help to solve the actual CPM tasks. In this specific case, it concerns the tools that support the creation of models for planning, cost allocation and profitability. The possibility to analyze other models as well as the data in the data warehouse represents an important part of these tools.

"End User Interface" - is the only layer where the end user comes into contact with the REMONA model. This layer contains cooperation supporting solutions and in particular individual types of output expected by the users of the solution. The key types of output in the end user layer include a portal with available dashboards for defined and authorized users, tools for interactive and operational reporting, etc. Forms, through which the user can enter defined data in the REMONA model, constitute an important part of the end user interface as well.

\subsection{Business Logic of the Model}

The business logic describes the concepts of planning, cost allocation, profitability management and related handled tasks. Its important part is also the link to dimensions, indicators and the user interface that is represented by the reporting layer, i.e. the user output layer.

When creating the model, we focused on the following three basic business tasks:

- Planning and the planning process phase, including planning workflow,

- Cost allocation,

- Profitability.

The common feature of Planning and planning process phase is that it is usually done in parts in several steps at different management levels, and different employees create the plan. Because of this fact, it is very important to correctly set up the planning process and especially to support it with planning workflow tools. If correctly set up, the workflow simplifies, speeds up and refines the 
planning process and makes it possible to quickly and easily identify the current status of the planning process, the person who has not yet fulfilled his tasks, etc.

From the point of view of Planning tasks, the authors consider the most important areas. The first one is the plan of product contribution that can initially be created based on the plan of revenues, e.g. from provided IT services for the first year. The second one is the plan of personnel costs represents the most significant cost of IT. In this context, the planning is done mainly based on the list of current employees, their positions and assumed changes in the number of employees. Onother one is the plan of center costs can be defined based on the list of general ledger accounts. This mainly concerns operating costs incurred from the regular operation of in-house centers. The fourth plan is the plan of fixed (CAPEX) and financial costs and depreciation represents the planning of investments, i.e. the acquisition of assets, the planning of a gradual reduction of the value of assets and its recognition as an expense, i.e. in the profit and loss account. Investments are primarily planned by individual centers that allocate investments to orders (products).

With respect to the tasks of Cost allocation, the authors found it important to describe the basic principles of cost allocation the way they are implemented in the REMONA model and should be handled in corporate informatics management. They are depicted in Fig. 3 and Fig. 4. The basic principle of cascade cost allocation is shown in Fig. 3. The abbreviations CC1-CC4 represent cost centers the way they may exist in a company. E.g. CC1 can be described as Administration (assets, building, etc.), CC2 as the IT Department, etc. "Cost Centers" must be always set as a dimension so that their number could be dynamically changed, based on the needs of the implementing company. As a result, individual types of cost are set.

\begin{tabular}{|l|l|l|l|l|l|}
\hline CostiCost center (CC) & $\mathbf{C C 1}$ & $\mathbf{C C 2}$ & $\mathbf{C C 3}$ & $\mathbf{C C 4}$ & $\mathbf{C C n}$ \\
\hline Employees & & & & & \\
\hline Hardware & & & & & \\
\hline Software & & & & & \\
\hline Trainings & & & & & \\
\hline Energy & & & & & \\
\hline$\ldots 1$ & & & & & \\
\hline$\ldots 2$ & & & & & \\
\hline Sum & & & \\
\hline \hline
\end{tabular}

Figure 3 - Principle of Cost Allocation

Fig. 4 presents the application of the ABC (Activity-Based Costing) method, which is based on total costs divided by type and, based on defined Drivers, further subdivides them into "Activities" and "Processes" that create a product or service. Total costs are then compared with "Revenues." "Revenues" are added to the calculation as an external element.

From the point of view of cost allocation, the model provides unique funkctionality. The first one is recognition of costs through cascade allocation. It 
concerns costs that cannot be directly allocated to products. Model provides an environment for the allocation of costs to products. Provides for a solution containing both allocation and the reporting basis for evaluation and analyses.

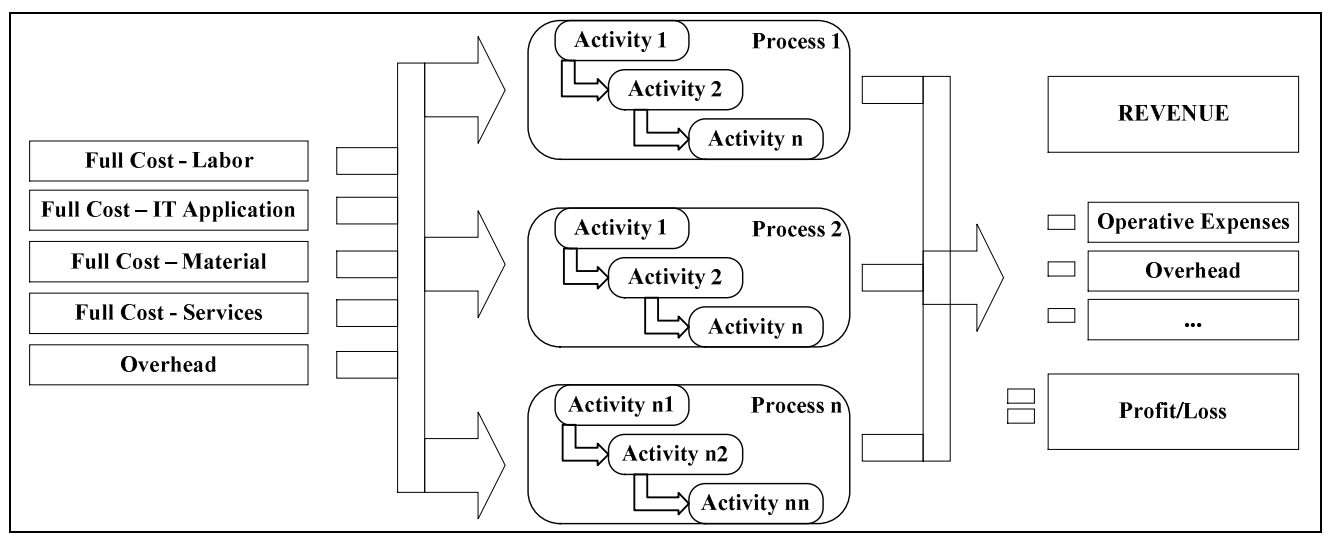

Figure 4 - Principle of Cost Allocation

\subsection{Data Model}

The data model is primarily based on consolidated data sources that are usually represented in companies as the "Company Data Warehouse." In the case that the structure, details or contents of the data in the warehouse are not in compliance with the needs of the analytical tasks that will be performed in the proposed model, it will be possible to use other data sources, such as e.g. external sources or data sources from other company applications. It is always necessary to prepare data integration tools for data migration and transformation. The quality of data is always dealt with in data processing. The so-far mentioned two layers are not the primary goal of the proposed model and will always be specific for each implementation.

The conceptual data model is divided into four comprehensive parts that are further specified all the way to the physical data model that is implemented in the selected database technology. The conceptual model is divided into "Finance and Managerial Accounting", "Operating Data", "Cost Allocation and Planning" and "Other". Each area covers a specific area. "Cost Allocation and Planning" covers in particular data connected with the setting of cost allocation parameters, which include the setting of the dimensions "Cost Center", "Cost Drivers" and "Activities and Processes". "Operating Data" are data arising from the regular activity of a company, such as the sale of goods and services. "Finance and Managerial Accounting" focuses on data sources related to financial and managerial accounting. 


\subsection{Service Parameters}

In proposing the model and implementing the entire system, it is necessary to first answer several key questions, the recognition of which affects the preparation of the proposed model. All these questions represent service parameters that must be taken into consideration so that the proposed solution could be configured and easily adapted to the needs and goals of the company that implements it. The main questions that we considered in the proposed model with respect to the parameterization of the solution are as follows:

- What key indicators are required for the management of the economics of corporate informatics? How are they interconnected with the achievement of the system of goals of a company as a whole? Are any in use at present?

- What are the current or expected main problems in the economics and management of the operation and of the development of corporate informatics and what are their solution priorities?

- Has the level of maturity of the processes of corporate informatics management been analyzed and what are the results?

- What level of detail will be necessary for analytical tasks in the management of the economics of corporate informatics?

- How is the cost of informatics monitored, and what is the position of cost analysis in corporate informatics management?

These questions are crucial for the practical solution and for the implementation of the system in corporate architecture and in corporate informatics management. It is obvious that the answers to these questions will vary from company to company. Based on their varying, it will be necessary tomodify the proposed solution by means of parameters and adapt and adjust the proposed model to the needs and requests of the representatives of the companies where it will be implemented.

The actual parameterization of the solution means, that users can dynamically creates hierarchies in dimensions, implement new indicators into the solution and create new outputs from the solution, based on user requests. Wery important is independency on primary data sources that serve as a data source for "REMONA Data Warehouse" and are always specific for a concrete company due to different data sources and automatization of the solution where output data can be prepared both based on a scheduled task set up for a certain time and based on a customer's ad-hoc request.

\section{VALIDATION AND KEY SUMMARIES}

The model was verified in two international companies working in the area of Consulting Services and the area of Automotive Industry (Maryska, 2014). Targets of both case studies were verification, validation and improvement of the 
proposed REMONA Model. Names of the companies are not published - all provided data is marked as a trade secret.

Key users identified the following facts which needed to be adjusted in the solution:

- amend the solution by including a new dimension Channel - requirement accepted and implemented,

- amend the solution by including new metrics - requirement accepted and implemented,

- amend the description of the rules which are part of the solution requirement accepted, description addressed outside this paper with regard to its limited scope,

- expand the set of pre-prepared reports - requirement rejected, it is not possible to implement all the company's requirements.

During the pilot implementation, the author identified several key factors that affected its implementation. The most important factors were identification of the requirements and expectations of key users, identification of the roles (and parts of these roles) that can support the proposed REMONA Model, the complexity of the data sources that need to be first understood and then cleaned, consolidated and recorded in the database via the transformation procedures (ETL), the comprehensive of the allocation rules, which can require quite complex solution parameterisation, the complexity of the dimensions and their hierarchy, which can require quite complex solution parameterisation and can subsequently affect the definition of the allocation rules, and various reporting requirements, which may make it necessary to create new reports according to the needs and requirements of the specific company.

One key area for every company is the cost aspect of implementing such a model. The costs in MD (Man Days) related to the implementation of this model were approximatelly 15 MDs. This number can be broken down into several areas. The first set of areas included the analysis of the existing solution + the identification of data for DWH, which amounted to 3 MDs of work, the analysis of the configuration needs, which took $1 \mathrm{MD}$, and the analysis of the solution extension (2 MDs). The second set included adjustment of the solution, including the proposal and implementation of DWH/ETL/Reporting, which took $5 \mathrm{MDs}$, and the configuration of the solution, which represented 2 MDs of work. The last part of implementation was testing, which needed 4 MDs. The total implementation time was 15 MDs. Total implementation costs can be calculated as a 15 MDs multiplied by the daily rate.

The savings achieved by implementing the model depend on the salary of the given company's employees. The savings are mainly in the form of a reduction to the amount of time needed for analyses and and of easy access to required information on daily/monthly bases without manual work, since all activities for providing this information are automated. 
The most variable elements of the implementation are expansion analysis, solution adjustment and testing. These may change according to the specifics and needs of the target company. The model is proposed so that in terms of the basic functionality it can allow its implementation WITHOUT extensive additional adjustments. The objective of the solution is that it can be implemented with less costs than 20 MDs.

\section{CONCLUSIONS}

The proposed theoretical concept and the apparatus of the REMONA model have been developed as a software application in chosen technology, which was used in the pilot implementation of the REMONA model in selected foreign companies. The pilot implementation in the companies mentioned in case studies 1 and 2. has proven that the proposed REMONA model simplifies the processing and analyzing of certain economic tasks that are presently considered crucial. The REMONA application can mainly be used in companies oriented on services and in production. Its advantages lie mainly in:

- The processing and interconnection of CPM and BI, including the assumptions and problems with implementing the solution in this area;

- The identification of selected methodologies and models related to the tackled issue and their mutual comparison;

- The identification of key indicators that should be used in cost allocation, profitability and related analytical tasks;

- The proposal of dimensions that are necessary for solving the mentioned economic tasks;

- The methodology of the implementation of the proposed model in a company - the specification of implementation procedure, including the procedures and options of adaptation of the proposed model to the characteristics of a target company.

The reference model that will help to increase awareness about the relationship between corporate informatics and other organizational units of a company through the proposed drivers and activities that corporate informatics provides and other units of a company use. The model enables to put into operation the tool supporting the management's decision-making in corporate informatics.

The proposed REMONA model will help the companies that will implement it in their corporate informatics management to simplify and speed up their internal analytical processes. It will mainly allow to provide more:

- Provide more quickly information about the cost allocation and profitability of individual projects, products, services, etc.;

- Provide more detailed information about the cost allocation and profitability of individual projects, products, services, etc.; 
- Provide more accurate information about the cost allocation and profitability of individual projects, products, services, etc.;

- Plan faster and more accurately and reliably thanks to a pre-defined workflow based on a selected dimension (usually an organizational structure dimension);

- Forward comments to the planners in the case that a plan needs to be redone;

- Arrange well and check easily the individual planning steps and the meeting of defined deadlines;

- Use pre-prepared automatic reporting combining the aforesaid benefits and allowing users to easily and quickly obtain needed information in needed details.

The pilot implementation and consultations with key users in companies have confirmed that the basic principle of the model and the method of its implementation are correct.

The importance of this model for theory and practise is based on fact, that this model takes into accout the best experience from existing models and methods. These are evolved and extended not only for theoretical concepts but also for best practices gained from practical implementations and validations. The most important points of the model is ability of fast implementation into selected company. The most important precondition of this fast implementation is fact, that company has qulity data sources and key financial processes are set.

\section{ACKNOWLEDGMENTS}

This paper is supported by the Research project IP400040 provided by the Faculty of Informatics and Statistics, University of Economics, Prague.

\section{REFERENCES}

Advanced Performance Institute, 2016. Performance Management - what is it?. [online] Available at: <http://www.ap-institute.com/what-is-performancemanagement.aspx $>$ [Accessed 31 May 2016].

Antonová, B. and Zapletalová, Š., 2014. The economic crisis and company management: influences and consequences. E+M, Ekonomie a Management, [ejournal] XVII(1), pp.4-18. http://dx.doi.org/10.15240/tul/001/2014-1-001.

Balocco, R., Ciappini, A. and Rangone, A., 2013. ICT Governance: A Reference Framework. Information Systems Management, [e-journal] 30(2), pp.150-167. http://dx.doi.org/10.1080/10580530.2013.773808.

Bjerge, B., Clark, N., Fisker, P. and Raju, E., 2016. Technology and Information Sharing in Disaster Relief. PLOS ONE, [e-journal] 11(9), e0161783. http://dx.doi.org/10.1371/journal.pone.0161783. 
Chrissis, M.B., Konrad, M. and Shrum, S., 2011. CMMI for Development: Guidelines for Process Integration and Product Improvement. 3rd ed. Upper Saddle River, NJ: Addison-Wesley Professional.

Cokins, G., 2009. Performance Management: Integrating Strategy Execution, Methodologies, Risk, and Analytics. Hoboken, N.J: Wiley.

Dimon, R., 2013. Enterprise Performance Management Done Right: An Operating System for Your Organization. Hoboken, New Jersey: Wiley.

Doucek, P. Maryska, M. and Nedomova, L., 2016. The Reference Model for Cost Allocation Optimization and Planning for Business Informatics Management. In: A.M. Tjoa, L.D. Xu, M. Raffai and N. Novak, ed. 2016. Research and Practical Issues of Enterprise Information Systems. Vienna, 13-14. December 2016. Switzerland: SpringerLink. pp.253-262. http://dx.doi.org/10.1007/978-3-319-49944-4_19.

Doucek, P., Maryska, M. and Nedomova, L., 2013. Informační management v informační společnosti. Praha: Professional Publishing.

Eckerson, W.W., 2010. Performance Dashboards: Measuring, Monitoring, and Managing Your Business. New York: Wiley.

Ernst \& Young, 2015. Technology risk: are your IT controls an asset or a liability? [Available at: <http://www.ey.com/PK/en/Issues/Operationaleffectiveness/IT-effectiveness/Global-Risk_Risk-Issues_Technology-Risk> [Accessed 31 May 2016].

Grembergen, W.V. and Haes, S.D., 2001. Measuring and Improving Information Technology Governance through the Balanced Scorecard. Message posted at: < https://www.researchgate.net/publication/251848095_Measuring_and_Improving _Information_Technology_Governance_through_the_Balanced_Scorecard> [Accessed 31 May 2016].

Isaca, 2012a. COBIT 5 for Information Security. Rolling Meadows, IL: Isaca.

Isaca, 2012b. COBIT 5 Framework. Rolling Meadows, IL: Isaca.

ITIL, 2001. ITIL: Service Strategy 1. London: TSO.

Keating, M., 2016. Beyond Labor Arbitrage to Achieving Business Value from IT08-ProfIT. [online] Freeborders. Available at: $<$ http://www.freeborders.com.cn/wp-content/uploads/08-ProfIT.pdf> [Accessed 31 May 2016].

Maryska, M. 2014. Referenční model optimalizace nákladové alokace a plánování pro řízení podnikové informatiky. Habilitation Thesis. University of Economics in Prague, Faculty of Informatics and Statistics.

Menken, I., 2011. Itil® Foundation Complete Certification Kit - Study Book and eLearning Program. Brisbane: Emereo Pty Ltd. 
MNsure, 2012. Cost Allocation Methodology = Information Technology cost Items. [pdf] State of Minnesota. Available at: $<$ https://www.mnsure.org/assets/Grant-CostAllocation-2012-08_tcm34182321.pdf $>$ [Accessed 31 May 2016].

Novotny, O. 2003. Aplikace metrik v referenčním modelu ř́zení podnikové informatiky. Ph. D. University of Economics in Prague, Faculty of Informatics and Statistics.

Parmenter, D., 2010. Key Performance Indicators (KPI): Developing, Implementing, and Using Winning KPIs. 2nd ed. Hoboken, N.J: Wiley.

Peffers, K., Tuunanen, T., Rothenberger, M. and Chatterjee, S., 2007. A Design Science Research Methodology for Information Systems Research. Journal of Management Information Systems, [e-journal] 24(3), pp.45-77. http://dx.doi.org/10.2753/MIS0742-1222240302.

Popesko, B., 2010. Metodika aplikace kalkulace Activity-Based Costing v průmyslových firmách. E+M, Ekonomie a Management, 1, pp.103-114.

Potter, K., 2009. Key Issues for Cost Optimization. [online] Gartner. Available at: $<$ https://www.gartner.com/doc/923830/key-issues-cost-optimization> [Accessed 31 May 2016].

Solodovnikova, D. and Kozmina, N., 2011. Determining Preferences from Semantic Metadata in OLAP Reporting Tool. In: J. Grabis and M. Kirikova, ed. Local Proceedings of the 10th International Conference on Perspectives in Business Informatics Research (BIR'11). Riga, Latvia, 6-8 October 2011. Berlin, Heidelberg: Springer.

Tavadyan, A.A., 2012. Internvals of Uncertainity of Economy. Moscow: Nauka.

Varian, H.R., Farrell, J. and Shapiro, C., 2005. The Economics of Information Technology: An Introduction. Cambridge, New York: Cambridge University Press.

Ventana Research, 2012. Smarter IT Cost Allocation. [online] Ventana Research. Available at: <http://www.ventanaresearch.com/blog/commentblog.aspx? id $=3133>$ [Accessed 31 May 2016].

Vorisek, J. and Pour, J., 2012. Management podnikové informatiky. Praha: Professional Publishing.

Vorisek, J. and Pour, J., 2015. Model for Management of Business Informatics. In: Current Issues of Science and Research in the Global World. Wien, 27-28 May 2014. London: Taylor \& Francis Group.

Vorisek, J., Pour, J. and Buchalcevova, A. 2015. Management of Business Informatics Model - Principles and Practices. E+M, Ekonomie a Management, [e-journal] 18(3), pp.160-173. http://dx.doi.org/10.15240/tul/001/2015-3-014. 
Wade, D. and Recardo, R., 2001. Corporate Performance Management. Boston: Taylor \& Francis.

Wagner, J., 2009. Měření výkonnosti. Praha: Grada Publishing.

Wibral, M., Pampu, N., Priesemann, V., Siebenhühner, F., Seiwert, H., Lindner, M., Lizier, J.T. and Vicente, R., 2013. Measuring Information-Transfer Delays. PLOS ONE, [e-journal] 8(2), e55809. http://dx.doi.org/ 10.1371/journal.pone.0055809.

\section{ABOUT AUTHORS}

Miloš Maryška has graduated at the Faculty of Informatics and Statistics at the University of Economic, Prague, in Information Technologies in 2006. In year 2010 has graduated in Applied Information Technologies and gained degree $\mathrm{Ph} . \mathrm{D}$. Since 2015 he is working as an associate professor at the Department of Information Technologies at the Faculty of Informatics and Statistics at the University of Economics, Prague. Within his pedagogic and research work he focuses on management of economics of business informatics, Business Intelligence and ERP systems. He is co-author of 5 books, and author and coauthor of several conference papers and in journal articles. In the company VIGRe as a Project manager - team leader.

Petr Doucek - Head of the Department of System Analysis, University of Economics, Prague, full professor since 2007 in Informatics. His research and education activities are focused on information security, project management and managerial science. He has been and is the principal investigator of two projects funded by Czech Science Foundation or The Ministry of Education, Youth and Sports of the Czech Republic and investigator on further seven projects as team member. He is actual a member of several program committees of conferences in Europe, America and Asia. He participated on approximately 30 projects for Czech and international companies. Member of Czech Society for System Integration, International Organization for Standardization (SC27 ISO Information technology security). Orcid.org/0000-0002-5647-661X.

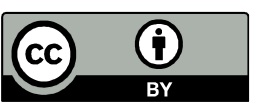

(C) 2017 by the authors. Submitted for possible open access publication under the terms and conditions of the Creative Commons Attribution (CC-BY) license (http://creativecommons.org/licenses/by/4.0/). 